\title{
A FORMAÇÃO DE PROFESSORES PARA O ENSINO PROFISSIONAL NO BRASIL: A CONSTRUÇÃO DE UM CAMINHO
}

\author{
A. C. R. SOUZA*, M. C. F. ANDRADE e A. F. S. AGUIAR \\ Instituto Federal de Educação, Ciência e Tecnologia do Amazonas - IFAM \\ prof.acsouza@gmail.com*
}

Artigo submetido em outubro/2014 e aceito em dezembro/2014

DOI: $10.15628 /$ rbept.2014.3553

\section{RESUMO}

Este artigo apresenta um estudo documental e bibliográfico sobre a Formação de Professores para o Ensino Profissional no Brasil. Ancorado na legislação brasileira e em literatura pertinente ao assunto num contexto histórico dos últimos 30 anos com os marcos referenciais da formação de professores para o ensino profissional que nos remete a uma visão sistêmica do processo formativo deste ensino. Perpassa-se pela reforma do ensino de primeiro e segundo graus com a Lei no 5.692, de 11/08/1971 e a formação técnicoprofissional com a integração completa do ensino profissional ao sistema regular de ensino pela equivalência entre os cursos profissionalizantes e o propedêutico. Analisamos também o Decreto-Lei no 11.892 de 29 de dezembro de 2008 sobre a criação de trinta e oito institutos Federais de Educação, Ciência e Tecnologia para promover uma educação de excelência através do ensino, pesquisa, extensão e inovação tecnológica. Como cerne do estudo discute-se sobre a formação de professores para o ensino profissional e tecnológico, e o que se observou na trajetória da legislação sobre o assunto, nas últimas décadas, é uma morosidade na proposição de ações efetivas para a formação deste professional.

PALAVRAS-CHAVE: Formação de professores, Ensino profissional e tecnológico, Legislação brasileira.

\section{PEDAGOGICAL KNOWLODGE AND THE HISTORY OF SCIENCE IN THE FORMATIVE PROCESS OF TEACHERS ON PROFESSIONAL EDUCATION: BUILDING A WAY}

\section{ABSTRACT}

This article presents a documental and bibliografical study of teacher's training on professional education in Brazil. We based the study on Brazil's legislation and on relevant literature to the subject in a historical context of the last 30 years, focusing on important theoretical frameworks to the training of these teachers to the professional education which takes us to a systemic view of the formative process of this education. We will go through the education reform on elementary and middle school with the law 5.692 from Agust 11th 1971 and the technical professional education with complete integration of the professional system to the regular
\end{abstract}

system of education trough equivalence between professional courses and the propaedeutic. We also analyzed the law 11.892 from December 29th 2008 that creates thirty eight Federal Institute of Science and Technology to promote an excellent education through education, research, culture and technological innovation. The main objective of this study was to discuss teacher's training on professional and technological education and the trajectory of the legislation on the subject in the last decades and analyze the slowness of effective actions that focus on training these professionals.

KEYWORDS: teacher's training, professional and technological education, brazilian legislation. 


\section{INTRODUÇÃO}

Discorrer sobre a formação de professores para o ensino profissional e tecnológico para construir suas bases epistemológicas em construção, exigiu um olhar minucioso, critico e reflexivo, pois pensar esta formação no Brasil é remeter nossas preocupações àquele profissional que na cotidianidade de sua profissão forma o cidadão para responder às demandas do mundo do trabalho de um mercado exigente: O professor.

O objetivo deste artigo é apresentar um estudo sobre a Formação de Professores para o Ensino Profissional no Brasil: A Construção de um Caminho, que busca pela normatização e referenciais sobre a formação de professores para este ensino e como esta formação se concretizou na história por meio da legislação da educação brasileira, com questões que nos remetem ao problema investigado: Como esta formação foi sistematizada e quais os marcos históricos sinalizados nos últimos 30 anos? Quais perspectivas? Quais construções?

O estudo trás para discussão os subtemas: A Reforma do ensino de primeiro e segundo grau, Lei n ${ }^{\circ}$ 5.692, de 11 de agosto de 1971 e a formação técnico-profissional; A criação de trinta e oito Institutos Federais de Educação, Ciência e Tecnologia e como cerne do estudo a formação de professores para o ensino profissional e tecnológico: um caminho em construção e as considerações finais. Trata-se de um estudo documental com coleta de dados restrita a documentos escritos (Legislação da Educação Brasileira), como fontes primárias, caracterizandose como pesquisa bibliográfica ou de fontes secundárias para identificar na literatura as contribuições científicas pertinentes ao tema específico à área (LAKATOS \& MARCONI, 2010, p. 157; MALHEIROS, 2011, p. 81-82).

\section{A REFORMA DO ENSINO DE PRIMEIRO E SEGUNDO GRAUS, LEI N 5.692, DE 11/08/1971 E A FORMAÇÃO TÉCNICO-PROFISSIONAL}

No ano de 1959, as Escolas Industriais e Técnicas são transformadas em autarquias, ganham autonomia didática e de gestão, intensificam a formação de técnicos, mão de obra indispensável diante da aceleração do processo de industrialização que ocorre no governo do Presidente Juscelino Kubitschek (1956-1961) coma marca do aprofundamento da relação Estado e economia. No entanto, o quadro formal de competências da educação profissional muda com a aprovação da Lei de Diretrizes e Bases da Educação, n 4.024, de 20 de dezembro de 1961.

Para definir o regulamento das escolas Técnicas Federais, foi promulgada a Lei $\mathrm{n}^{\circ} 3.552$, de 16 de fevereiro de 1959, que dispõe sobre a nova organização escolar e administrativa dos estabelecimentos de ensino industrial do Ministério da Educação e Cultura. O ensino industrial foi aprovado pela Lei ${ }^{\circ}$ 47.038, de 16 de outubro de 1959 (SCHMIDT \& ORTH, 2013, p. 38).

A história evidencia que o período de 1964 a 1971 da ditadura militar foi marcado por profundas mudanças históricas significativas, com o período de industrialização, que necessitava de pessoas para atuarem no mercado de trabalho que soubessem ler e escrever. Nesse período surgiu a Lei de Diretrizes e Bases da Educação, n 5.692/71 de 11 de agosto de 1971 que reconheceu a integração completa do ensino profissionalizante ao sistema regular de ensino pela equivalência entre os cursos profissionalizantes e o propedêutico para prosseguimento nos estudos rompendo com a tradição secular que não vinculava o Ensino Médio estritamente ao 
mundo do trabalho profissional e tornava obrigatória a aquisição de uma profissão [...] (NASCIMENTO E COLARES, 2008, p. 2).

Por isso,

O foco inicial da política educacional do regime militar é o ensino superior, com o intuito de racionalizar e flexibilizar a oferta, de modo a atender um maior contingente de alunos. A reforma do ensino do 10 e 20 graus, por sua vez, orientase para a contenção dessa demanda através da formação de quadros técnicos de nível médio, por meio da profissionalização (VIEIRA, 2008, p. 125).

A Reforma do ensino de 10 e 2 o graus promovida pela Lei $n^{\circ}$ 5692/71 destaca dois eixos de grande importância: o aumento da obrigatoriedade escolar de quatro para oito anos e a inclusão do ensino profissionalizante no curso de nível médio ou 20 grau, com a inclusão das massas populares até então em grande parte, excluídas da escola. Uniu o antigo primário ao ginasial, suprimindo os exames admissionais; criou a escola única profissionalizante e reestruturou o curso supletivo (MOURÃO, 2013, p. 69. 73).

A habilitação profissional passa a ser compulsória em substituição à equivalência entre os ramos secundário e propedêutico introduzindo modificações na estrutura do ensino, entre elas a pretensa eliminação do dualismo existente entre a escola secundária e a escola técnica, originando-se uma escola única de 1 으 e 20 graus, para a educação básica geral juntamente com a preparação para o trabalho. Ao ensino de 1 ㅇ grau, cabia a formação geral, a sondagem vocacional e a iniciação para o trabalho; enquanto que o ensino de 20 grau passa a constituir-se, indiscriminadamente, de um nível de ensino cujo objetivo primordial é a habilitação profissional (SCHMIDT \& ORTH, 2013).

No entanto, conforme N. S. A. Triviños a Reforma foi questionada:

[...] principalmente a elite, que mais se sentiu prejudicada, uma vez que o ensino médio passava a ser profissionalizante. De fato, por reforma, o ensino médio clássico científico deixou de preparar os jovens para o ingresso à universidade, tornando-se também profissionalizante. Isso desgostou tanto a classe alta como a média que viam seus filhos deixando de serem preparados para o ingresso à universidade, preconizando um movimento que, na década de 1980 redundou na alteração do mesmo, primeiramente para possibilitar aos colégios do ensino médio que assim o quisessem, uma formação mais genérica e que, posteriormente foi relegado a um plano secundário (2006, p. 121).

À uma análise sociológica desta reforma, aplicam-se considerações de P. Bourdieu (1998) sobre a escola que partem da constatação de uma relação entre as desigualdades sociais e escolares que, por mais que se democratize o acesso ao ensino por meio da escola pública e gratuita, continuará existindo uma forte correlação entre as desigualdades sociais, sobretudo, culturais, e as desigualdades ou hierarquias internas ao sistema de ensino. Alguns estariam numa condição mais favorável do que outros para atenderem às exigências, muitas vezes implícitas, da escola.

No processo de mudanças a Lei no 6.545 de 30 de junho de 1978, transforma as Escolas Técnicas Federais do Paraná, Minas Gerais e Celso Suckow da Fonseca no Rio de Janeiro em Centros Federais de Educação Tecnológica - CEFET's. o que confere àquelas instituições mais uma 
atribuição, formar engenheiros de operação e tecnólogos, estendendo-se mais tarde às outras instituições. Eis o que diz a Lei:

\begin{abstract}
Art. 1ㅇ - As Escolas Técnicas Federais de Minas Gerais, com sede na cidade de Belo Horizonte; do Paraná, com sede na Cidade de Curitiba; e Celso Suckow da Fonseca, com sede na Cidade do Rio de Janeiro, criadas pela Lei $n^{\circ} 3.552$, de 16 fevereiro de 1959, alterada pelo Decreto-lei $\mathrm{n}^{\circ} 796$, de 27 de agosto de 1969, autorizadas a organizar e ministrar cursos de curta duração de Engenharia de Operação, com base no Decreto-lei $n^{\circ} 547$, de 18 de abril de 1969, ficam transformadas em centros Federais de Educação Tecnológica (BRASIL, 1978).
\end{abstract}

A legislação de 20 de novembro de 1996 a Lei n 9.394 - Lei de Diretrizes e Bases da Educação (LDB) dispõe sobre a Educação Profissional em capítulo separado da educação básica com relação à regulamentação da educação profissional regulamentada pelo Decreto $\mathrm{n}^{\circ} 2.208$, de 17/04/1997 com a criação do programa de Expansão da Educação Profissional (PROEP). No governo do Presidente Luís Inácio Lula da Silva (2004) a Lei $n^{\circ} 2.028 / 97$ - que trata da separação entre ensino médio e a educação profissional é substituído pelo Decreto $n^{\circ} 5.154$ de 23 de julho de 2004.

\title{
2.1 Decreto-Lei $n^{\circ} 11.892$ de 29 de dezembro de 2008
}

Por este Decreto Lei o Presidente da República Luís Inácio Lula da Silva com o Ministro da educação Fernando Haddad cria trinta e oito Institutos Federais de Educação, Ciência e Tecnologia com a missão de promover uma educação de excelência através do ensino, pesquisa, extensão e inovação tecnológica, visando à formação do cidadão crítico, autônomo, empreendedor e comprometido com o desenvolvimento social, científico e tecnológico do país.

Alicerçado em uma vasta rede de instituições de ensino profissional e tecnológico do Governo Federal com ampliação desde 1909, quando da criação pelo Decreto Lei $N^{\circ} 7.566$, de 23 de setembro de 1909, sancionado pelo Presidente da República Nilo Peçanha, com a criação de uma Escola de Aprendizes e Artífices, para as dezenove capitais dos Estados da Federação, possibilitando uma educação profissional primária, pública e gratuita para os pobres e desvalidos da fortuna [...] (SOUZA, 2015).

\section{A FORMAÇÃO DE PROFESSORES PARA O ENSINO PROFISSIONAL E TECNOLÓGICO: UM CAMINHO EM CONSTRUÇÃO}

Na perspectiva de formação de professores, a primeira iniciativa em reposta a essa demanda como nos diz L. R. S. Machado (2008, p. 11) veio de Wenceslau Brás, à época, Presidente da República que, em 1917 criou a Escola Normal de Artes e Ofícios Wenceslau Brás no antigo Distrito Federal do Rio de Janeiro para formar dois tipos de professores, os mestres e contramestres para as escolas profissionais e as professoras, de trabalhos manuais para as escolas primárias.

É importante a compreensão de que a formação e a capacitação de professores para o ensino profissional e tecnológico devem, portanto, ir além da aquisição de técnicas didáticas de transmissão de conteúdos para os professores e de técnicas de gestão para os dirigentes, devendo privilegiar a formação no âmbito das políticas públicas do país, principalmente as educacionais, 
numa perspectiva de superação do modelo que se deve priorizar mais o ser humano do que, simplesmente, as relações do mercado e o fortalecimento da economia (MOURA p. 30).

Mas como organizar esta formação? Na tentativa de sistematizar a formação de docentes para a educação profissional e tecnológica o autor acima citado afirma que é necessário fazer esforços em três direções: 1. A formação dos profissionais que já estão em exercício; 2 . Os que estão em processo de formação; 3. Os que se formarão no futuro, devendo esta formação partir de dois grandes eixos: O primeiro está relacionado com a área de conhecimento específica graduação/pós-graduação strictu-sensu nas instituições de ensino superior. O segundo, refere-se à formação pedagógica e às especificidades das áreas de formação profissional que compõem a esfera da educação profissional e tecnológica.

O que se evidencia então é que com a LDB n 4.024/61 em seu Artigo 59, dois caminhos separados foram estabelecidos para a formação de professores. Em faculdades de filosofia, ciências e letras, para o magistério no ensino médio. Em cursos especiais de educação técnica, os que se habilitassem para disciplinas do ensino técnico o que passou a vigorar somente em 1967 e 1968.

Mas quem é este profissional para o qual a legislação mencionada faz poucas alusões de formação? É o professor, aquele que transita nas mais diversas áreas do saber e do ensino, especificamente o professor da educação profissional com um qualitativo complementar como descrito por C. M. Rehem:

Aquele que Que ensina trabalhar, que educa para o desenvolvimento de uma dada profissão. $O$ que significa além das capacidades exigidas à categoria professor, que se the acrescentem capacidades outras, relacionadas com os saberes referentes aos processos produtivos e ao mercado de trabalho, às dinâmicas e às lógicas (e ilógicas) que estão a regê-los (2009, p. 107).

Nesse processo educativo o professor deve assumir outra atitude, forjada a partir de outro tipo de formação, que deve ser crítica, reflexiva e orientada pela responsabilidade social. Nesta perspectiva ele deixa de ser um transmissor de conteúdos acríticos e definidos por especialistas externos para assumir uma atitude problematizadora e mediadora do processo ensinoaprendizagem sem, no entanto, perder sua autoridade nem, tampouco, a responsabilidade com a competência técnica dentro da área de conhecimento (FREIRE, 1996).

O Parecer $n^{0} 12 / 67$ do CFE foi o primeiro dispositivo de regulamentação dos cursos especiais de educação técnica previstos pela LDB $n^{\circ} 4.024 / 61$ com o objetivo de esclarecer a finalidade destes cursos. Com base neste Parecer, a Portaria Ministerial $n^{\circ} 111 / 68$ tais cursos seriam destinados aos diplomados em nível superior ou em nível técnico em cujos currículos figurassem disciplinas escolhidas para lecionar com o mínimo de 720 horas-aula. Cursos destinados a formar instrutores teriam pelo menos, 200 horas-aula. $O$ artigo 59 regulamentado pelo Parecer no 479/68 do CFE, que estabeleceu a obrigatoriedade de um currículo mínimo e as orientações do Parecer no 262/62 que fixava a duração da formação dos professores do ensino médio geral, incluindo as posteriores disposições que viessem modificar, esclarecer ou substituir tal dispositivo (MACHADO, 2008, p. 11).

O comentário que se faz aos Pareceres ressaltados no parágrafo anterior é a ideia de uma flexão da tendência que vinha se formando com relação ao esquema $3+1$ que corresponde a três 
anos de núcleo comum e um ano para a especialização profissional, representando uma novidade uma vez que os cursos especiais eram concebidos sem referência a currículo mínimo, demonstrando que esse parecer tinha a intenção de diminuir a separação existente entre formação docente para o ensino técnico e formação docente para o ensino médio.

A Reforma Universitária, instituída pela Lei no 5.540/68, que elevaria o nível de exigência que em seu Artigo 30, determinou que a formação de professores para o ensino de segundo grau, de disciplinas gerais ou técnicas teria que se dar somente em cursos de nível superior, vindo a ser flexibilizada já no ano seguinte pela Lei no 464/69 que instituiu normas complementares à Lei no 5.540/68 em seu Artigo 16 determinou que, enquanto não houvesse número suficiente de professores e especialistas formados em nível superior, a habilitação para a docência no ensino técnico poderia ser feita mediante exame de suficiência realizado em instituições oficiais de ensino superior indicada pelo Conselho Federal de Educação (CFE) sendo esta uma forma de regularizar a situação da grande maioria dos professores das escolas técnicas da época.

Em razão da urgência no equacionamento da defasagem entre determinação legal e situação real, surgiu a Lei no 655/69 para autorizar os órgãos técnicos do Ministério da Educação MEC, encarregados da administração e coordenação do Ensino Técnico Agrícola, Comercial e Industrial, a organizar, em nível superior e para as respectivas áreas, os cursos de Formação de Professores para o Ensino Técnico; que o MEC, além da função normativa, passou a ser diretamente executante da formação de professores para essa área criando a Fundação Centro Nacional de Aperfeiçoamento de Pessoal para a Formação Profissional.

Em decorrência, vemos que com a Portaria Ministerial no 339/70 foram desenhados cursos emergenciais, denominados Esquema I destinado à complementação pedagógica a portadores de diploma de nível superior e Esquema II - destinado a técnicos diplomados e incluíam disciplinas pedagógicas do Esquema I e as de conteúdo técnico específico (MACHADO, 2008, p. 12).

Com relação à regulamentação das cargas horárias para os cursos de formação de professores para a educação profissional o Parecer no 74/70 do CFE, estabeleceu que os cursos de formação de professores para o ensino técnico deveriam ser ministrados em 1.600 horas/aula integralizáveis em nove meses. Para candidatos com a formação técnica específica em nível médio ou superior, o curso poderia ser reduzido para 800 horas/aula integralizáveis em cinco meses.

Os governos militares à época davam muita importância à planificação central. Além dos planos de desenvolvimento econômicos, havia planos educacionais, geralmente quinquenais. Então, para a formação de professores do ensino técnico, sendo estabelecidas algumas diretrizes de planificação. O Parecer $n^{\circ} 151 / 70$ do CFE aprovou o plano para formação de professores para as disciplinas profissionais do ensino técnico industrial.

Entre 1979 e 1982, do CFE emitiu diversos pareceres: sobre registro de professores oriundos dos Esquemas I e II, sobre autorização para a oferta de cursos emergenciais. Já o Parecer $n^{\circ}$ 1.004/80 do CFE é referente à adaptação desses cursos aos termos da Resolução $n=3 / 77$, do CFE, (licenciaturas) incluindo resolução sobre o assunto, que consta na Resolução CFE $n^{\circ} 1 / 81$. Mas, em vez das licenciaturas, os esquemas se impunham, chegando a Secretaria de Educação Superior - SESU/MEC n 47/79 a aprovar, em 1979, um plano para cursos emergenciais.

A partir da Lei n 9.394, de 20 de dezembro de 1996, Lei de Diretrizes e Bases, em seu Capítulo IV artigos 39-42 a educação profissional aparece em capítulo separado da educação 
básica. No referente à formação de professores para a educação profissional e tecnológica o artigo 61 estabelece apenas que a formação de profissionais da educação dos diferentes níveis e modalidades de ensino dar-se-á mediante a associação entre teorias e práticas, mediante a capacitação em serviço, e que é preciso aproveitar a formação e as experiências anteriores desses profissionais em instituições de ensino e em outras atividades incluído pela Lei $n^{\circ} 12.014$, de 6 de agosto de 2009.

Com a Lei no 2.208 surge também o disciplinamento dos programas especiais de formação pedagógica pelo MEC após ouvir o Conselho Nacional de Educação e a Resolução CNE n 2/97, que dispõe sobre os programas especiais de formação pedagógica de docentes para as disciplinas do currículo do ensino fundamental, do ensino médio e da educação profissional em nível médio, destinados aos diplomados em cursos superiores. Fica instituída a carga horária de pelo menos, 540 horas, incluindo a parte teórica e prática, esta com duração mínima de 300 horas o que representa um rebaixamento significativo da carga horária em relação ao que se vinha sendo praticado nos cursos especiais de formação docente para a educação profissional o que poderá confirmar pouca valorização da formação teórica e pedagógica desse professor e que a parte teórica do programa seja oferecida na modalidade à distância.

\section{CONSIDERAÇÕES}

É importante reafirmar que investir na formação de professores para a formação profissional e tecnológica no Brasil, é apresentar propostas para sua concretização. Como explicitadas por D. H. Moura (2008, p. 31) existem dois grandes eixos na organização desta formação. O primeiro está relacionado com a área de conhecimento específico, adquirida na graduação, cujo aprofundamento é estratégico e deve ocorrer por meio de programas de pósgraduação, principalmente stricto sensu, oferecidos pelas instituições de educação superior, nacionais e estrangeiras, não somente por iniciativa do profissional, mas impulsionada também pelas necessidades das instituições. O outro eixo refere-se à formação didático-político pedagógico e às especificidades das áreas de formação profissional que compõem a esfera da EPT. Não é suficiente que o docente tome a iniciativa de formação, é necessário que as instituições criem políticas de formação para a cultura da formação docente.

Estes dois grandes eixos consideram três situações distintas quanto aos grupos aos quais se destina essa formação. Aos profissionais que atuam na EPT; os graduados que já atuam como docentes da EPT, mas não têm formação específica nessa esfera educacional; os futuros profissionais que ainda começarão a formação inicial.

Nesse caso, é fundamental que o docente tenha uma formação específica que lhe aproxime da problemática das relações entre educação e trabalho e do vasto campo da educação profissional e, em particular, da área do curso no qual atua ou atuará para estabelecer as conexões entre essas disciplinas e a formação profissional específica, corroborando para a diminuição da fragmentação do currículo. Sugere-se que ela ocorra, inicialmente, por meio de cursos de pós-graduação lato sensu como base de futuros cursos stricto sensu com características diferenciadas dos cursos de especialização correntes no país para a função a que se destinam. É necessário que a carga horária ultrapasse o limite mínimo de 360 horas com estágios de prática docente e de observação e/ou prática no mundo do trabalho na área profissional em que o docente atua ou atuará após a conclusão desta formação (MOURA, 2008, p. 32-33). 
O que se observa na trajetória da legislação sobre o assunto, nas últimas décadas é uma morosidade na proposição de ações efetivas para a formação dos professores da Educação Profissional e Tecnológica.

\section{REFERÊNCIAS}

\subsection{Legislação}

1. BRASIL. Decreto no 7.566, de 23/09/1909. Cria nas capitais dos Estados da República Escolas de Aprendizes Artífices, para o ensino profissional primário e gratuito. Disponível em: <http://goo.gl/CPEVUm >. Acesso em fev. 2015.

2. BRASIL. Lei no 4.024, de 20/12/1961. Lei de Diretrizes e Bases da Educação: LDB. Fixa as Diretrizes e Bases da Educação Nacional. Disponível em: <http://goo.gl/93AH90>. Acesso em mar. 2015.

3. BRASIL. Lei no 5.540 de $28 / 11 / 1968$. Fixa normas de organização e funcionamento do ensino superior e sua articulação com a escola média, e dá outras providências. Disponível em: <http://goo.gl/0kCXLG>, Acesso em mar. 2015.

4. BRASIL. Decreto no 464, de 11/021969. Estabelece normas complementares à Lei no 5.540, de 28/11/68 e dá outras providências. Disponível em: <http://goo.gl/QiExRR>. Acesso em mar. 2015.

5. BRASIL. Decreto $n^{\circ} 655 / 69$. Autoriza os órgãos técnicos do Ministério da Educação, organizar e coordenar o ensino Técnico Agrícola, Comercial e industrial. Disponível em: http://goo.gl/L6vFLD. Acesso em mar. 2015.

6. BRASIL. Portaria Ministerial no 339/70. Trata sobre os desenhos dos cursos emergenciais. Esquema I, II e III. Disponível em: http://goo.gl/gAM6Zx. Acesso em mar. 2015.

7. BRASIL. Resolução CFE no 3/77. Fixou o currículo mínimo para a graduação. Disponível em: <http://goo.gl/WzaOrO>. Acesso em mar. 2015.

8. BRASIL. Lei no 6.545, de 30/06/1978. Dispõe sobre a transformação das Escolas Técnicas Federais de Minas Gerais, do Paraná e Celso Suckow da Fonseca em Centros Federais de Educação Tecnológica e dá outras

9. BRASIL. Constituição da República Federativa do Brasil. 1988. Disponível em: <http://goo.gl/8Fkaie>. Acesso em mar. 2015.

10. BRASIL. Lei no 9.394, de 20/12/1996. Estabelece as diretrizes e bases da educação nacional. Disponível em: <http://goo.gl/zYbkN1>. Acesso em fev. 2015.

11. BRASIL. Decreto no 2.208, de 17/04/1997. Regulamenta o § 20 do art. 36 e os art. 39 a 42 da lei no 9.394, de 20/12/1996 que estabelece as diretrizes e bases da educação nacional. Disponível em: <http://goo. .gl/qzYo3p>. Acesso em mar. 2015.

12. BRASIL. Resolução CFE no 2/97. Dispõe sobre os programas especiais de formação pedagógica de docentes para as disciplinas do currículo do ensino fundamental, do ensino médio e da educação profissional em nível médio. Disponível em: <http://goo.gl/6hWbzX>. Acesso em mai. 2015.

13. BRASIL. Decreto no 5.154, de 23/07 2004. Regulamenta o § 20 do art. 36 e os art. 39 a 41 da 
Lei no 9.394, de 20/12/1996 que estabelece as diretrizes e bases da educação nacional, e dá outras providências. Disponível em: <http://goo.gl/j4HnT7>. Acesso em mar. 2015.

14. BRASIL. Lei no 11.892, de 29/12/2008. Lei da Rede Federal de Educação Profissional, Científica e Tecnológica. Institui a Rede Federal de Educação Profissional, Científica e Tecnológica, cria os Institutos Federais de Educação, Ciência e Tecnologia, e dá outras providências. Disponível em <http://goo.gl/Aahmsz>. Acesso em fev. 2015.

15. BRASIL. Lei no 12.014, de 6//2009. Altera o art. 61 da Lei no 9.394, de 20 de dezembro/1996, com a finalidade de discriminar as categorias de trabalhadores que se devem considerar profissionais da educação. Disponível em: <http://goo.gl/q5PcOe>. Acesso em mai. 2015.

16. Parecer CFE no 479/68. Estabelece obrigatoriedade de seguir currículo mínimo na formação de professores Ensino Médio. Disponível em: http://goo.gl/unD2QU. Acesso em mar. 2015.

17. Parecer CFE no 74/70. Estabelece sobre a carga horária dos cursos d formação de professores para a educação profissional. Disponível em: <http://goo.gl/tmr6R7>. Acesso em mar. 2015.

18. Parecer CFE no 151/70. Estabelece diretrizes de planificação para a formação de professores. Disponível em: <http://goo.gl/2XYr5S>. Acesso em mar. 2015.

19. Parecer CFE no 1.004/80. Trata sobre registro de professores oriundos dos Esquemas I e II, sobre autorização para a oferta de cursos. <http://goo.gl/ohb7>. Acesso em 15 mar. 2015.

\subsection{Livros/Artigos}

20. BOURDIEU, P. Escritos de Educação. Petrópolis: Vozes, 1998.

21. FREIRE, P. Pedagogia da autonomia. São Paulo: Paz e Terra, 1996.

22. LAKATOS, E. M \& MARCONI, M. de A. Fundamentos de Metodologia Científica. 7. ed. São Paulo: Atlas, 2010.

23. MALHEIROS, B. T. Metodologia da pesquisa em educação. Rio de Janeiro: LTC, 2011.

24. MACHADO, L. R. S. Diferenciais inovadores na formação de professores para a educação profissional. Revista Brasileira da Educação Profissional e Tecnológica/Ministério da Educação, Secretaria de Educação Profissional e Tecnologia. V. 1, n. 1, (jun. 2008). Brasília: MEC, SETEC, 2008. Anual. Disponível em: <http://goo.gl/bPDvi7>. Acesso em fev. 2015.

25. MOURA, D. H. Educação Básica e Educação Profissional e Tecnológica: Dualidade Histórica e Perspectivas de Integração. In HOLOS ano 23, Vol.2. Revista Eletrônica do CEFET-RN/2007. Disponível em <http://goo.gl/DkyCLc>. Acesso em fev. 2015.

26.

A formação de docentes para a educação profissional e tecnológica. Revista

Brasileira da Educação Profissional e Tecnológica. Revista Brasileira da Educação Profissional e Tecnológica/Ministério da Educação, Secretaria de Educação Profissional e Tecnológica. V. 1, n. 1, (jun. 2008). Brasília: MEC, SETEC, 2008. Disponível em: <http://goo.gl/Z1fNw1>. Acesso em fev. 2015.

27. MOURÃO, Arminda R. B; [et. al]. A Educação Profissional na Lei 5.692/71. In A Educação Profissional na Região Norte. Reflexões e críticas. Manaus: Edua, 2013.

28. NASCIMENTO e COLARES. Análise da eficiência da Lei 5.692/71 na formação dos Trabalhadores de Guarapuava sob a perspectiva de Consciência para a cidadania e qualificação para o Trabalho. Disponível em: <http://migre.me/p1itD>. Acesso em mar. 2015. 
29. REHEM, C. M. Perfil e formação do professor de educação profissional técnica. São Paulo: SENAC, 2009.

30. SCHMIDT, M. A.; ORTH, M.A. Ações Políticas e Sociais da Educação Profissional: Alguns aspectos históricos. In B. Tec. Rio de Janeiro, v. 39, n. 3, set./dez.2013.

31. SOUZA. A. C. R. Escola de Aprendizes Artífices do Amazonas: Os caminhos de sua implantação e consolidação, em 1909-1942. São Paulo, 2002. Dissertação (Mestrado em História da Ciência). Pontifícia Universidade Católica de São Paulo, PUC/SP.

32. . Histórico do IFAM. Disponível em: <http://goo.gl/pmZ35y>. Acesso em mar. 2015.

33. TREVIÑOS, A. N. S. [et. al]. A agonia do (a) educador (a) sul-rio-grandense: Histórias de vida. Porto Alegre: UFRGS, 2006.

34. VIEIRA, S. L. Desejos de reforma: legislação educacional no Brasil Império e República. Brasília: Líber Livro, 2008. 